\title{
ENHANCED ORAL BIOAVAILABILITY OF TENOFOVIR FROM IONOTROPICALLY GELLED MICROBEADS
}

\author{
DHANDAPANI NAGASAMY VENKATESH*, PREETY RAO, RAMAN RAJESHKUMAR**
}

*Department of Pharmaceutics, ** Department of Pharmaceutical Biotechnology, JSS College of Pharmacy, (A Constituent College of JSS Academy of Higher Education \& Research) Udhagamandalam 643001. Tamil Nadu.

Email: nagasamyvenkatesh@jssuni.edu.in

Received: 30 Jan 2019, Revised and Accepted: 10 May 2019

\section{ABSTRACT}

Objective: The main objective of the present investigation was to develop the microbeads of tenofovir. Tenofovir, a BCS class III drug has a poor bioavailability of $25 \%$, and it is administered $300 \mathrm{mg}$ once a day. By incorporating the drug into a microparticulate carrier, it is expected that the dissolution profile and the oral bioavailability may be increased.

Methods: Reinforced gellan-chitosan and calcium chloride beads of tenofovir were prepared by ionotropic gelation method employing various different concentrations of gellan, chitosan, calcium chloride and tenofovir. The beads were evaluated for various physicochemical parameters such as particle size determination, drug entrapment efficiency, swelling studies, infrared spectroscopy study, differential scanning calorimetry, x-ray diffraction analysis, scanning electron microscopy, in vitro drug release study, cytotoxicity study and in vivo oral bioavailability studies.

Results: From the results, it can be concluded that the formulation TB-III exhibited higher drug entrapment efficiency (46.09 \pm 0.21$)$, a higher swelling index, sustained drug release for a period of $24 \mathrm{~h}$. The pharmacokinetic profile of the drug from microbeads exhibited an increased oral bioavailability (1.25 times higher than that of the pure drug), decreased elimination rate (1.32 times lesser for the drug in microbeads) with prolonged elimination half-life (1.32 times higher than pure tenofovir).

Conclusion: Tenofovir loaded microbeads demonstrated as a better delivery system for the modified release of drug and also to navigate the drawbacks associated with conventional therapy.

Keywords: Tenofovir, Gellan, Chitosan, Ionotropic gelation, Oral bioavailability

(c) 2019 The Authors. Published by Innovare Academic Sciences Pvt Ltd. This is an open-access article under the CC BY license (http://creativecommons.org/licenses/by/4.0/) DOI: http://dx.doi.org/10.22159/ijap.2019v11i4.32281

\section{INTRODUCTION}

Sustained release drug delivery system is an ideal approach that provides a uniform concentration of drug available at the site of absorption. Due to this unique property, the system tends to maintain appropriate plasma concentrations in the therapeutic range [1]. In the past few decades, scientists have given a greater effort in the development of novel drug delivery systems, which assures the targeting of drug to a particular area and to and maintain the required concentration to exhibit better therapeutic response [2]. In most of the incidences, the optimal therapeutic response is observed when adequate blood levels are maintained with minimal variation. Sustained release formulations are gained importance for the oral administration of drug owing to their maintenance of consistent blood levels. Among them, polymeric beads have gained attractive attention in these days owing to their unique property. Polymeric beads are particulate carriers in which the drug is dispersed in solution or crystalline form that facilitates the sustained release profile [3]. Microencapsulation technology facilitates an effective administration of drugs by improving their solubility profile, minimizing side effects and improving therapeutic response [4]. Improved therapeutic efficacy coupled with the reduced adverse effect is considered to be the most important aspects in future research work [5]. The utility of natural biodegradable polymers in sustained drug delivery still continues to be of interesting research area owing to their abundant natural availability, the capability to undergo any chemical modification and compatibility [6, 7]. Tenofovir, a nucleotide reverse transcriptase inhibitors (NtRTI's) approved by USFDA in 2001 for the treatment of human immunodeficiency virus infection (HIV), has oral bioavailability was reported to be in the range of $25-30 \%$ [8]. Tenofovir is administered $300 \mathrm{mg}$ once daily. Converting incorporating the drug in to a microbeads drug delivery system, it would be expected to improve the oral bioavailability and effectiveness in the anti-HIV therapy and better patient compliance. Therefore, the main purpose of this study was to formulate and evaluate tenofovir microbeads for improving the sustained the release of the drug, which in turn improve the oral bioavailability. Various parameters such as particle size determination, drug entrapment efficiency, swelling studies, infrared spectroscopy study, differential scanning calorimetry, x-ray diffraction analysis, scanning electron microscopy, in vitro drug release study, cytotoxicity study and in vivo bioavailability studies were systematically investigated.

\section{MATERIALS AND METHODS}

\section{Materials}

Tenofovir disoproxil fumarate was obtained as a gift from Laurus Labs (Visakapatinam, India). Gellan gum was purchased from SigmaAldrich Ltd, (Mumbai, India) and chitosan were procured from Sigma-Aldrich Ltd, (Mumbai, India). All other chemicals used in the study were of pharmaceutical or analytical grade.

\section{Preparation of microbeads containing tenofovir}

The reinforced microbeads of tenofovir were prepared by ionotropic gelation technique. Initially, gellan gum solution was prepared by dissolving gellan in deionized water and followed by heating it at 60 ${ }^{\circ} \mathrm{C}$. About $50 \mathrm{ml}$ of the gellan gel from each batch was taken separately and a different concentration of drug was dispersed uniformly in the gel maintained at $40^{\circ}$. With continuous stirring. The stirring was further continued until uniform dispersion of drug was achieved. The resultant homogenous slurry was dropped into a $50 \mathrm{ml}$ solution containing different concentrations of calcium chloride and chitosan, using a syringe $(21 \mathrm{G})$ under stirring condition. The stirring was continued for a certain period of time to improve the mechanical strength of the beads and also to prevent aggregation. The formed beads were separated from the solution by filtration and dried at $40^{\circ}$ C. The gellan beads with the exception of chitosan were also prepared using the aforesaid procedure. The details of the composition of microbeads, particle size and drug encapsulation efficiency of different formulations were shown in table 1. [9]

\section{Particle size determination}

The particle size of the beads was measured using a micrometer (Mitotuyo, Japan). The average diameter of 100 particles per batch was estimated. [9] 


\section{Drug entrapment efficiency (DEE)}

The drug content in the beads was estimated by digestion method, where a known quantity of ritonavir loaded beads $(20 \mathrm{mg})$ was pulverized in a glass mortar with pestle and incubated in $0.1 \mathrm{M} \mathrm{HCl}$ at room temperature for $1 \mathrm{~h}$ to extract the drug completely. The clear supernatant solution was assayed spectrophotometrically for drug content at the wavelength of $260 \mathrm{~nm}$. Supernatant from the empty beads was taken as blank. All samples were analyzed triplicate [9].

\section{Swelling studies}

The swelling properties of the beads were determined my mass measurement. Samples of beads of known weight ( $25 \mathrm{mg}$ ) were incubated with $25 \mathrm{ml}$ of swelling solution $(0.1 \mathrm{~N} \mathrm{HCl})$ and $25 \mathrm{ml}$ of phosphate buffer ( $\mathrm{pH}$ 6.8) allowed swelling at $37^{\circ} \mathrm{C}$. The swollen beads were then removed periodically, excess swelling solution was wiped using a dry filter paper and their final weight was determined using an electronic balance. The percentage of swelling of the beads was calculated using the formula.

$$
\% \text { of Swelling }=\frac{\text { final weight of the beads }\left(W_{2}\right) \text {-initial weight of the beads }\left(W_{0}\right)}{\text { intial weight of the beads }\left(W_{0}\right)} X 100
$$

\section{Infrared spectroscopy study (FTIR)}

Infrared spectra of tenofovir, blank gellan and chitosan microbeads and drug-loaded beads were performed using in $\mathrm{KBr}$ pellets using an FTIR spectrophotometer (Perkin-Elmer, Japan). The samples were scanned between in the range of 4000 to $400 \mathrm{~cm}^{-1}$.

\section{Differential scanning calorimetry analysis (DSC)}

DSC analysis was carried out to observe the changes if any during the formulation of beads. DSC of tenofovir, blank gellan and chitosan microbeads and drug-loaded beads were examined by using a thermal analyzer (TA instruments, Bangalore). The samples were heated from $50-200^{\circ}$ at a heating rate of $10^{\circ} \mathrm{C} / \mathrm{min}$ under constant purging of nitrogen at a flow rate of $50 \mathrm{ml} / \mathrm{min}$ respectively.

\section{X-ray diffraction analysis (XRD)}

$\mathrm{X}$-ray powder diffraction analysis of tenofovir, drug-loaded beads were carried out using the X-ray diffractometer (Jeol JDX $8030 \mathrm{X}$-ray diffractometer Tokyo, Japan) using Ni-filtered, CuK $\alpha$ radiation, a voltage of $40 \mathrm{kV}$ and a $25-\mathrm{mA}$ current. The scanning rate employed was $1 \% \mathrm{~min}$ and scanned over $2 \theta$ range of the 10 to $80^{\circ}$.

\section{Scanning electron microscopy (SEM)}

The surface morphology of the beads was examined using scanning electron microscope (Jeol, JSM, 35CF, Japan). The beads were mounted onto individual stab and then coated with carbon and gold (100 and $50 \AA$ thickness respectively). The coated samples were then observed under scanning electron microscope operated at $7 \mathrm{KV}$.

\section{In vitro drug release study}

In vitro drug release studies of ritonavir from beads were carried out using $0.1 \mathrm{M} \mathrm{HCl}(900 \mathrm{ml})$ USP paddle type dissolution apparatus (USP XXIII, Electrolab, Mumbai) at $50 \mathrm{rpm}$. A weighed quantity of beads equivalent to $50 \mathrm{mg}$ of drug was used in each test. At predetermined time intervals, a $5 \mathrm{ml}$ of samples were withdrawn and same volume of fresh media was replaced. The amount of drug release was analyzed at $260 \mathrm{~nm}$ after proper dilution if required.

\section{Release kinetics}

Different kinetic equations (zero order, first order and Higuchi's equations) were applied to interpret the release rate of the drug from the matrix system. The best fit with higher correlation $\left(r^{2}>0.98\right)$ was found with Higuchi's equation for all the formulations. Two factors, however, diminish the applicability of Higuchi's equation to matrix systems [10]. This model fails to allow for the influence of swelling of the matrix (upon hydration) and the gradual erosion of the matrix. Therefore, the dissolution data were also fitted to the well-known exponential Korsmeyer-Peppa's equation [11].

$$
\frac{M_{t}}{M_{\alpha}}=k t^{n}
$$

$M_{t} / M_{\alpha}$ is the fraction of drug release at time' $t$ ', ' $k$ ' is the kinetic constant and ' $n$ ' is the release exponent (indicating release mechanism). In addition, for determination of the exponent ' $n$ ', one must use only the initial portion of the release cure $\left(M_{t} / M_{\alpha}<0.6\right)$ [11]. Ritger and Peppas have defined the exponent ' $n$ ' as a function of the aspect ratio $(2 \mathrm{a} / \mathrm{l})$ defined as the ratio of diameter (2a) to thickness (l). For tablets, depending on the aspect ratios, ' $n$ ' values between 0.43 and 0.5 indicates Fickian (case I) diffusion mediated release, non-fickian (anomalous) release, coupled diffusion and polymer matrix relaxation occurs if $0.5<\mathrm{n}<0.89$, purely matrix relaxation or erosion-mediated release occurs for $n=1$ (zero order kinetics) and super case II type of release occurs for $n>0.89$ [12].

\section{In vitro cytotoxicity assay by MTT method}

The monolayer cell culture was trypsinized and the cell count was adjusted to $1.0 \times 10^{5}$ cells/ml using DMEM medium containing $10 \%$ FBS. To each well $100 \mu \mathrm{l}$ of diluted cell suspension (approximately 10000 cells/wells) was added. After $24 \mathrm{~h}$, when a partial monolayer was formed, the supernatant was flicked off. The monolayer was washed once with medium and $100 \mu \mathrm{l}$ of different test samples were added per well to the partial monolayer in the microtitre plates. The plates were then incubated at $37^{\circ} \mathrm{C}$ for $72 \mathrm{~h}$ under $5 \% \mathrm{CO}_{2}$ atmosphere and microscopic observations were recorded at every $24 \mathrm{~h}$. After $72 \mathrm{~h}$, the sample solutions in the wells were discarded and $20 \mu$ of MTT $(2$ $\mathrm{mg} / \mathrm{ml}$ ) in MEM-PR (MEM without phenol red) was added to each well. The plates were gently shaken and incubated with $5 \% \mathrm{CO}_{2}$ atmosphere at $37^{\circ} \mathrm{C}$ for $3 \mathrm{~h}$. The supernatant was removed and $50 \mu \mathrm{l}$ of iso-propranol was added to solubilize the formed formazan. The absorbance was measured using a microplate reader at a wavelength of $540 \mathrm{~nm}$. The percentage of growth inhibition was calculated using the formula.

$$
\% \text { of Growth viability }=\frac{\text { mean } O D \text { of individual test group }}{\text { mean } O D \text { of control group }} X 100
$$

\section{Bioavailability studies}

Albino rabbits (male) weighing approximately 1.0 to $1.5 \mathrm{~kg}$ were used for the oral bioavailability studies [13]. A randomized, two treatment, two period, two sequence, single dose cross over bioavailability study for the solution of tenofovir and tenofovir microbeads containing $21 \mathrm{mg}$ of pure drug in suspension form and microbeads was carried out in 6 healthy albino wister rabbits to prove the safety and efficacy of the formulations. The protocol of the study was approved by the institutional animal ethics committee (JSSCP/IAEC/M. PHARM/PH. CEUTICS/02/2016-17 dated $02 / 05 / 2016$ ). The animals were divided into three groups of six animals each. Prior to the study the animals were kept for fasting for Group I served as the control, group II pure drug in suspension form at a dose of $21 \mathrm{mg}$ and group III received microbeads containing drug of $21 \mathrm{mg}$. $0.5 \mathrm{ml}$ of blood was withdrawn from the marginal ear vein of the animals at the predetermined time intervals of $0,1,2,4$, 8,12 and $24 \mathrm{~h}$ using sterilized disposable syringes. The blood sample was collected in a ria vial containing the anticoagulant $(0.3$ $\mathrm{ml}$ of $11 \%$ sodium citrate) were centrifuged at $4000 \mathrm{rpm}$ for $4 \mathrm{~min}$ to separate plasma. The plasma samples were deprotinised using an equal volume of $10 \%$ perchloric acid and vortoxed for $2 \mathrm{~min}$. It was further centrifuged at $4000 \mathrm{rpm}$ for $4 \mathrm{~min}$ to separate the plasma and stored at $-20^{\circ} \mathrm{C}$ until further analysis. A reproducible analytical technique was developed for the estimation of the drug in the plasma samples. The HPLC system consisted of a stationary phase, Lichrospher C18 $(250 \times 4.6 \mathrm{~mm}$ i.d., $5 \mu)$, the mobile phase consisted of ammonium acetate buffer: acetonitrile (55:45), with a flow rate of $1 \mathrm{ml} / \mathrm{min}$, using a sample volume of $20 \mu \mathrm{l}$. The internal standard used was lopinavir. The detection was carried out at $260 \mathrm{~nm}$ using Shimadzu HPLC: Model LC-2010 A-HT autosampler. Various pharmacokinetic parameters such as $\mathrm{C}_{\max }, \mathrm{T}_{\max }, \mathrm{K}_{\mathrm{el}}, \mathrm{AUC}_{\mathrm{o}-\mathrm{t}}$ and $\mathrm{AUC}_{\mathrm{o}}$. $\alpha$ were estimated using PK1 and PK2 solutions.

\section{Statistical analysis}

Statistical analysis was performed using SPSS version 13.0. The pharmacokinetic parameters like $\mathrm{C}_{\max }, \mathrm{T}_{\max }, \mathrm{K}_{\mathrm{el}}, \mathrm{AUC}_{\mathrm{o}-\mathrm{t}}$ and $\mathrm{AUC} \mathrm{C}_{\mathrm{o}-\alpha}$ of the both the formulations are presented in mean \pm SD One way ANOVA (analysis of variance) was employed in the statistical analysis of the determined parameters in this study. Statistical significance was defined at $\mathrm{p}<0.05$. 


\section{RESULTS AND DISCUSSION}

\section{Particle size determination}

The microbeads were found to be smooth and free flowing in nature. The average particle size of the different batches of the formulation was varied from $616 \pm 2.23$ to $888 \pm 1.21 \mu \mathrm{m}$. This revealed that as the quantity of gellan increases, the sizes of the beads also increases proportionally due to the increase in the microviscosity of the polymer.

\section{Drug entrapment efficiency (DEE)}

The DEE was found to be in the range of $20.40 \pm 0.12 \%$ to $46.09 \pm 0.21 \%$. These results indicated that the DEE of beads increases with an increase in the concentration of the polymer. This could be explained by the fact that the ionized state of polymer concentration enables intense cross-linking results in higher encapsulation efficiency of the drug. Formulations containing chitosan exhibited higher encapsulation efficiency than the formulations not containing chitosan.

Table 1: Composition of tenofovir loaded microbeads, bead size and drug entrapment efficiency

\begin{tabular}{|c|c|c|c|c|c|c|}
\hline $\begin{array}{l}\text { Code of } \\
\text { formulation }\end{array}$ & $\begin{array}{l}\text { Drug } \\
\text { (mg) }\end{array}$ & $\begin{array}{l}\text { Gellan gum } \\
\text { (mg) }\end{array}$ & $\begin{array}{l}\text { Chitosan } \\
\text { (mg) }\end{array}$ & $\begin{array}{l}\text { Calcium chloride } \\
(\% \mathrm{w} / \mathrm{v})\end{array}$ & $\begin{array}{l}\text { Bead Size } \\
(\mu \mathrm{m})^{*}\end{array}$ & $\begin{array}{l}\text { Drug entrapment efficiency** } \\
\text { (DEE) } \%\end{array}$ \\
\hline TB-I & 50 & 50 & 50 & 2 & $701 \pm 2.12$ & $39.66 \pm 0.22$ \\
\hline TB-II & 50 & 100 & 50 & 2 & $801 \pm 1.13$ & $39.68 \pm 0.33$ \\
\hline TB-III & 100 & 50 & 50 & 2 & $724 \pm 3.21$ & $46.09 \pm 0.21$ \\
\hline TB-IV & 50 & 50 & 50 & 4 & $640 \pm 2.7$ & $38.44 \pm 0.32$ \\
\hline TB-V & 50 & 100 & 50 & 4 & $888 \pm 1.12$ & $27.66 \pm 0.44$ \\
\hline TB-VI & 100 & 50 & 50 & 4 & $728 \pm 2.12$ & $44.08 \pm 0.37$ \\
\hline TB-VII & 50 & 50 & - & 2 & $616 \pm 2.23$ & $20.40 \pm 0.12$ \\
\hline TB-VIII & 50 & 100 & - & 2 & $776 \pm 1.12$ & $25.20 \pm 0.22$ \\
\hline TB-IX & 100 & 50 & - & 2 & $701 \pm 1.34$ & $28.57 \pm 1.2$ \\
\hline
\end{tabular}

${ }^{*}($ mean \pm SD, $\mathrm{n}=100),{ }^{* *}($ mean $\pm \mathrm{SD}, \mathrm{n}=3)$

\section{Swelling studies}

In order to evaluate the swelling ability of beads at different $\mathrm{pH}$ conditions, the cross-linked beads exhibited a higher degree of swelling at acidic $\mathrm{pH}(0.1 \mathrm{M} \mathrm{HCl})$ than the phosphate buffer $(\mathrm{pH} 6.8)$ as shown in fig 1 and 2. The increase in swelling at acidic $\mathrm{pH}$ is mainly due to the protonation of chitosan; whereas the decrease in swelling at alkaline $\mathrm{pH}$ is due to the ionization of carboxyl group in the gellan as inner layer in beads. The rate of swelling is also governed by the concentration of the polymer and strength of calcium chloride solution used. Swelling of beads decreased with increased concentration of gellan in the gelling solution and increase with the concentration of calcium chloride solution.

\section{Infrared spectroscopy study (FTIR)}

The infrared spectra of tenofovir, blank gellan and chitosan microbeads and drug-loaded beads are shown in fig. 3-5. These spectra's revealed that no shifting of peaks was observed, indicating the stability of the drug during the encapsulation process. The principle peaks of tenofovir-OH at $3051 \mathrm{~cm}^{-1}, \mathrm{C}=\mathrm{N}$ at $1626.26^{-1}, \mathrm{C}=0$ $1756.25 \mathrm{~cm}^{-1}$ and $\mathrm{P}=0$ at $1262 \mathrm{~cm}^{-1}$. After interpretation through the above spectra with the drug-loaded microbeads, it was confirmed that there was no major shifting as well as no loss of functional peaks. From the spectra it was concluded that the polymer gellan gum and chitosan is found to be compatible in entrapping the drug. The decrease in the peak intensity of the formulation may be attributed to the fine dispersion of drug in the polymer matrix.

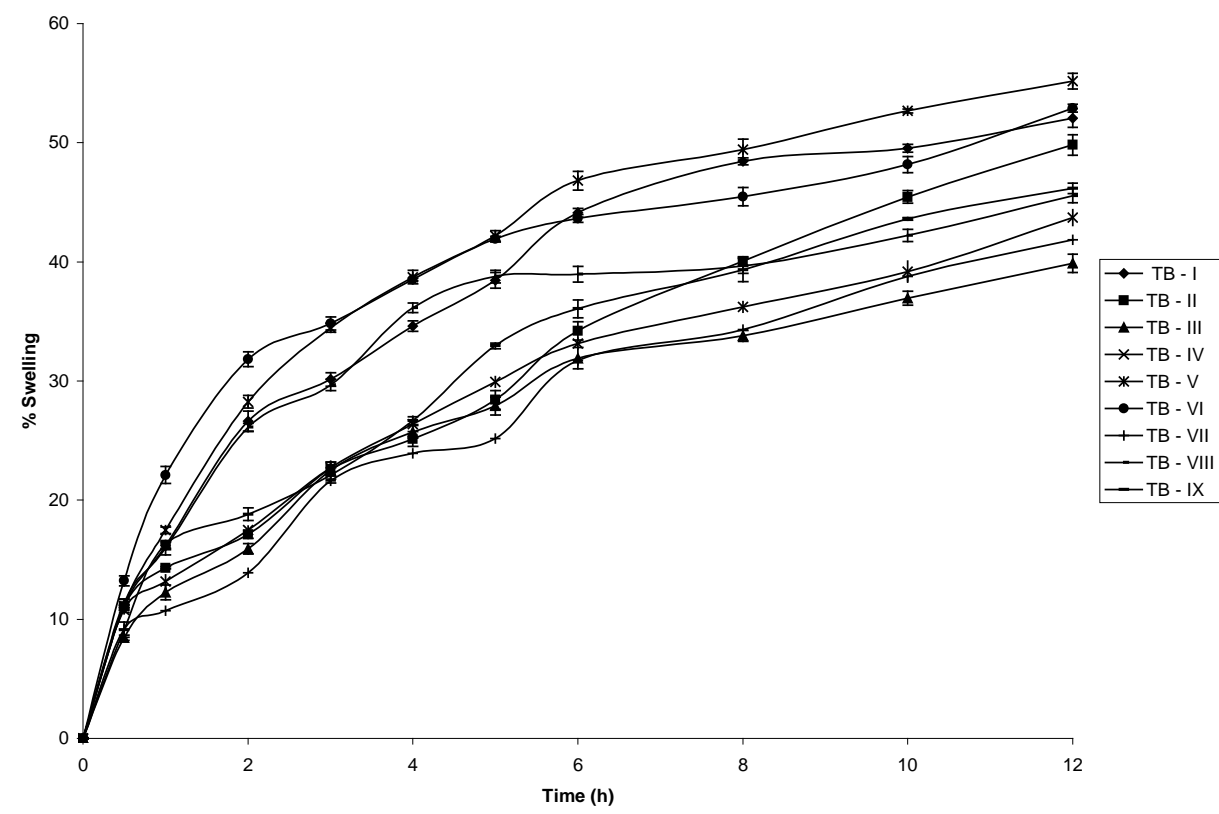

Fig. 1: Swelling studies of tenofovir microbeads in $0.1 \mathrm{M} \mathrm{HCl}($ mean \pm SD, $n=3$ ) 


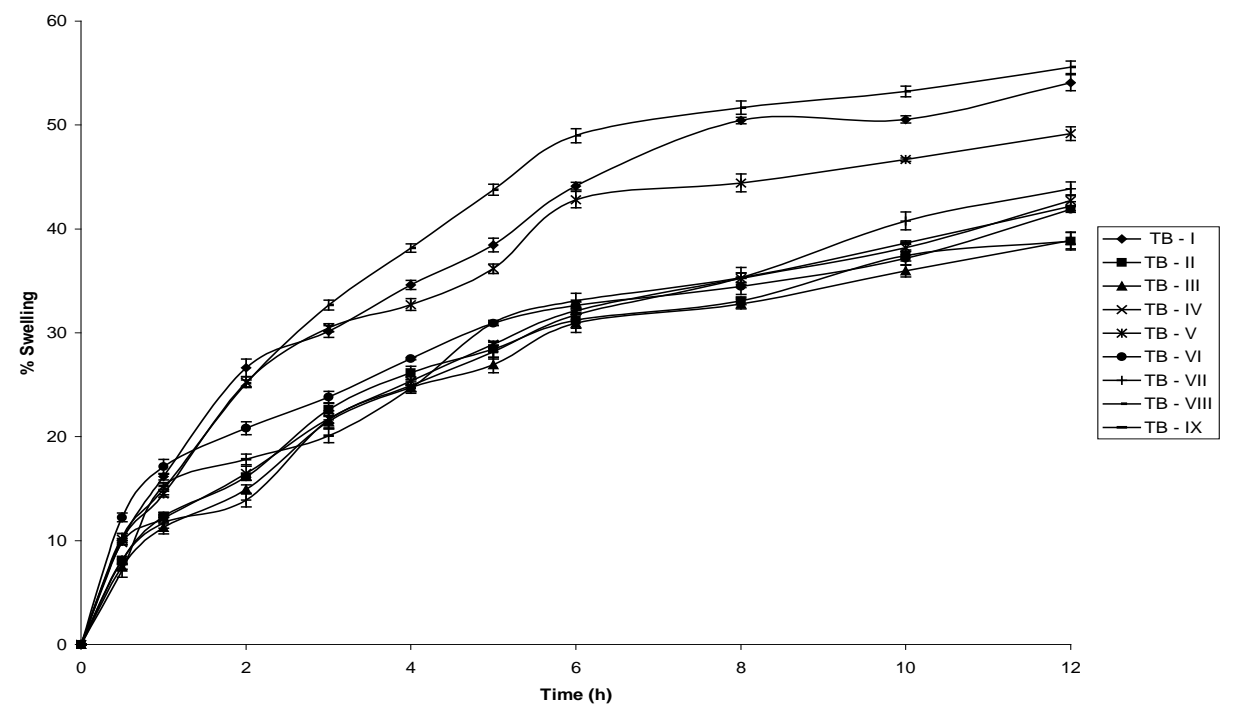

Fig. 2: Swelling studies of tenofovir microbeads in phosphate buffer (pH 6.8) (mean $\pm \mathrm{SD}, \mathrm{n}=3$ )

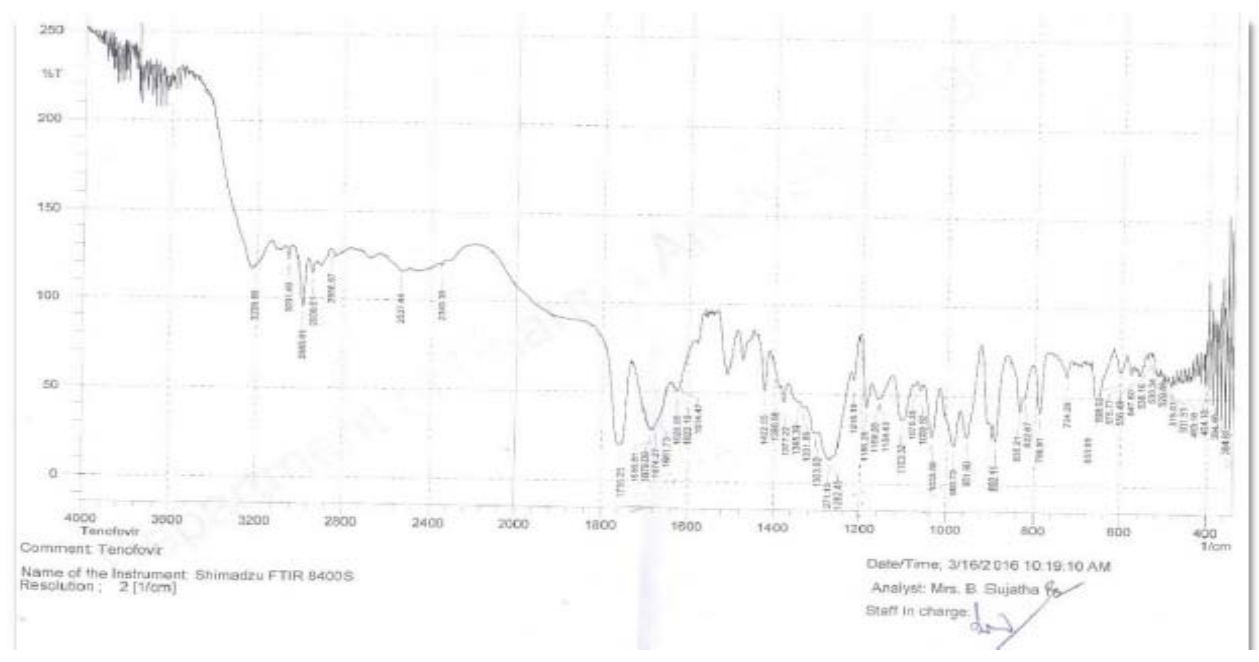

Fig. 3: Fourier transform infra red spectroscopy of tenofovir

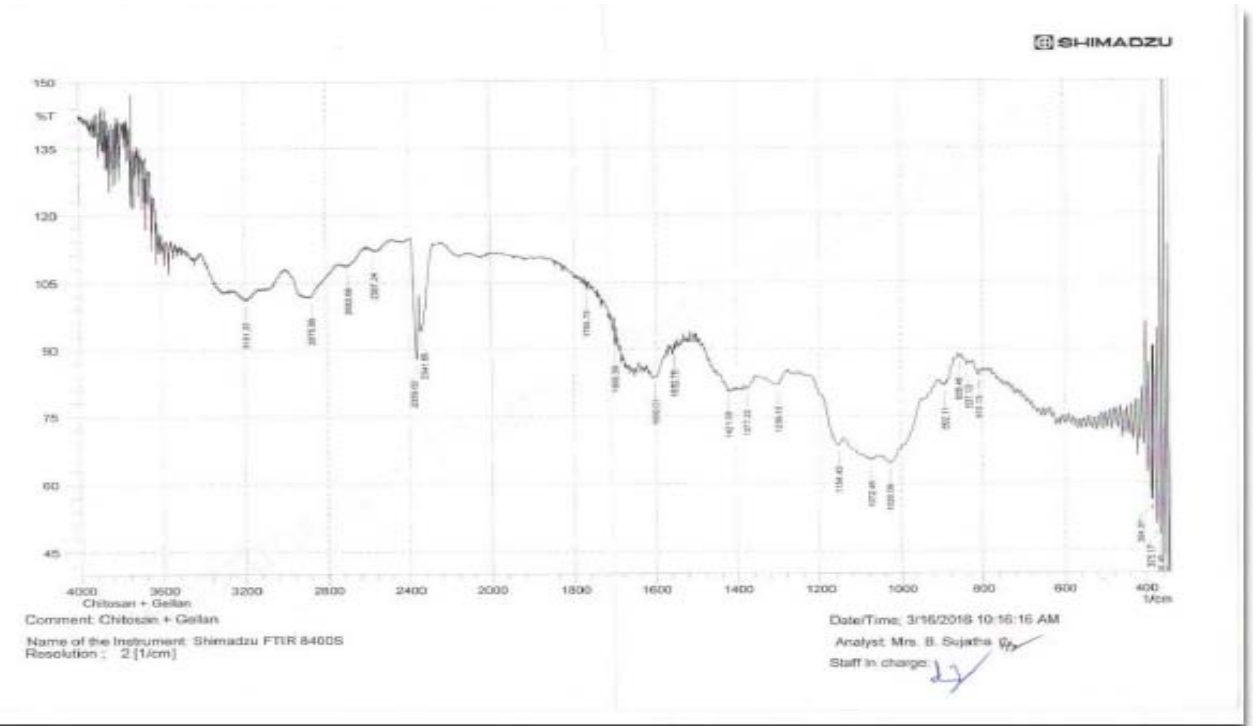

Fig. 4: Fourier transform infrared spectroscopy of blank microbeads 


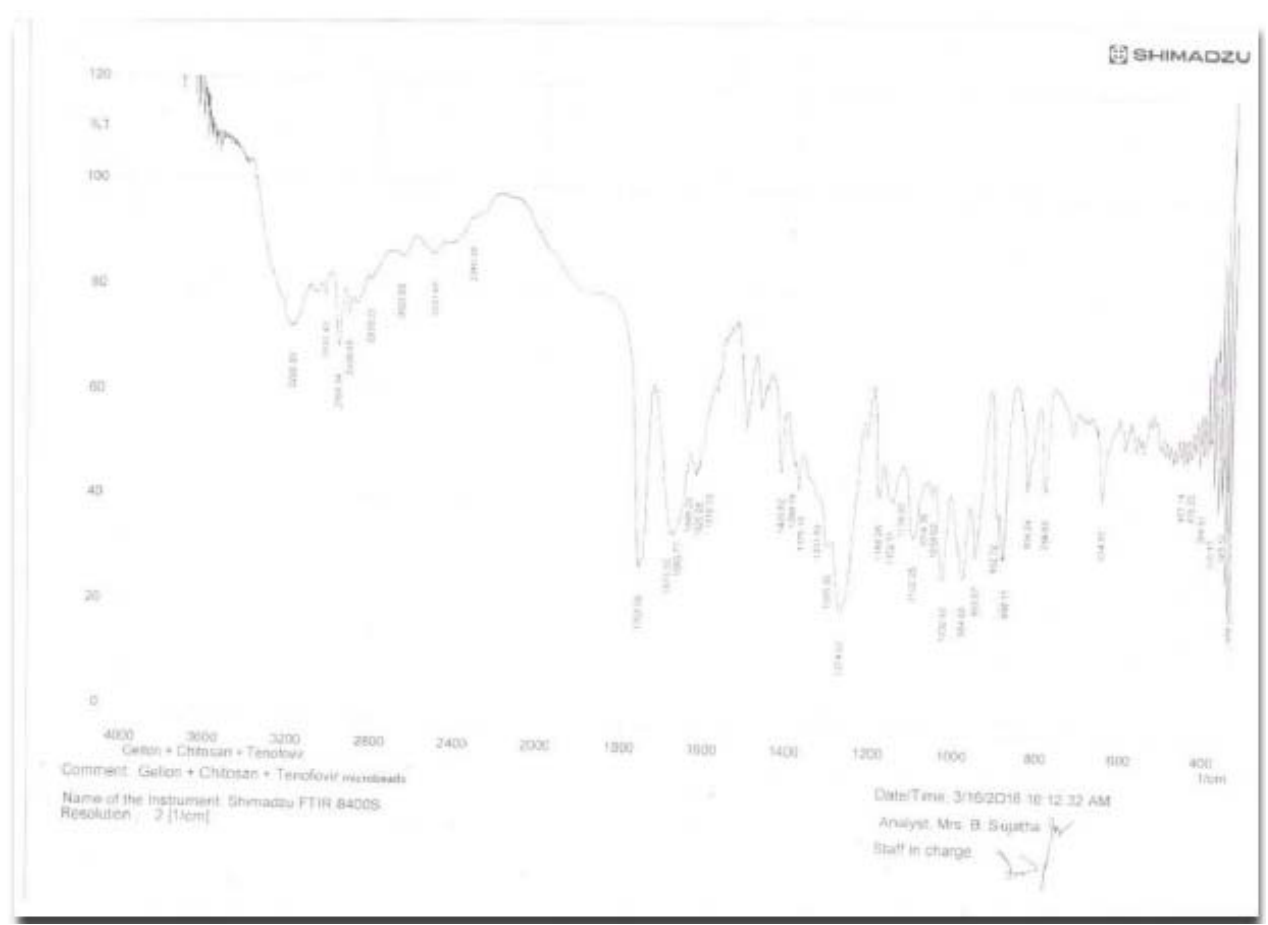

Fig. 5: Fourier transform infra red spectroscopy of tenofovir loaded microbeads

\section{Differential scanning calorimetry analysis (DSC)}

Fig. 6-8 illustrates the comparative DSC thermogram of tenofovir, gellan-chitosan beads, tenofovir loaded gellan-chitosan bead. The DSC thermogram of tenofovir showed a sharp endothermic peak corresponding to melting point at $119.91^{\circ} \mathrm{C}$. The sharp endothermic peak of the drug in microbeads has not appeared indicating that the drug was dispersed in an amorphous state in the polymer.

\section{$\mathrm{X}$-ray diffraction analysis (XRD)}

The X-ray powder diffraction patterns of drug and drug loaded microbeads are compared. The X-ray powder diffraction pattern of pure drug showed its own crystal peaks between $2 \theta$ of $10^{\circ}$ and $80^{\circ}$.
It was observed that the characteristic peaks of the drug were found to be absent in the drug entrapped gellan-chitosan beads indicates the probable decrease in the crystallinity of drug. The undefined, broad, diffused peaks with the low intensities for drug entrapped beads revealed that the conversion of drug from crystalline to amorphous form in the formulation fig 9-10.

\section{Scanning electron microscopy (SEM)}

The SEM of the drug-loaded beads were found to be irregular in shape having a smooth and dense surface with inward dent and shrinkage due to the collapse of the wall during dehydration. The fibrous network was also observed on the surface of the beads as shown in fig 11-12.

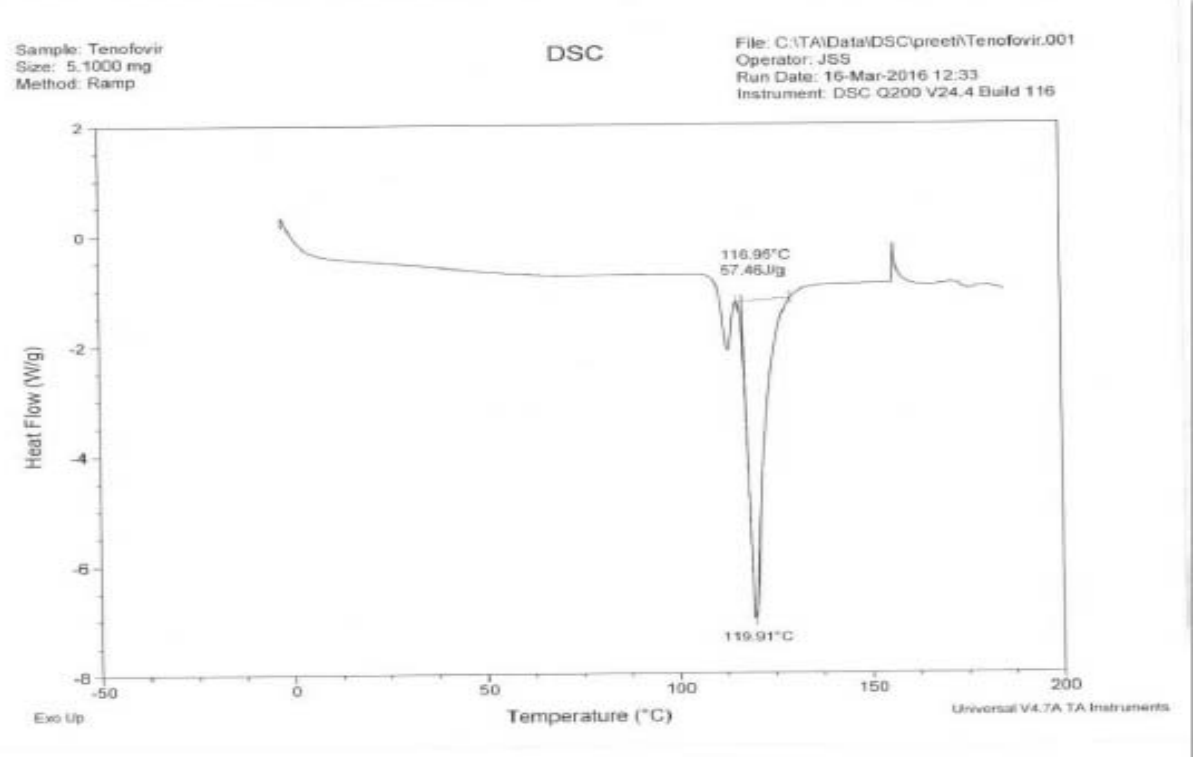

Fig. 6: Differential scanning calorimetry of tenofovir 


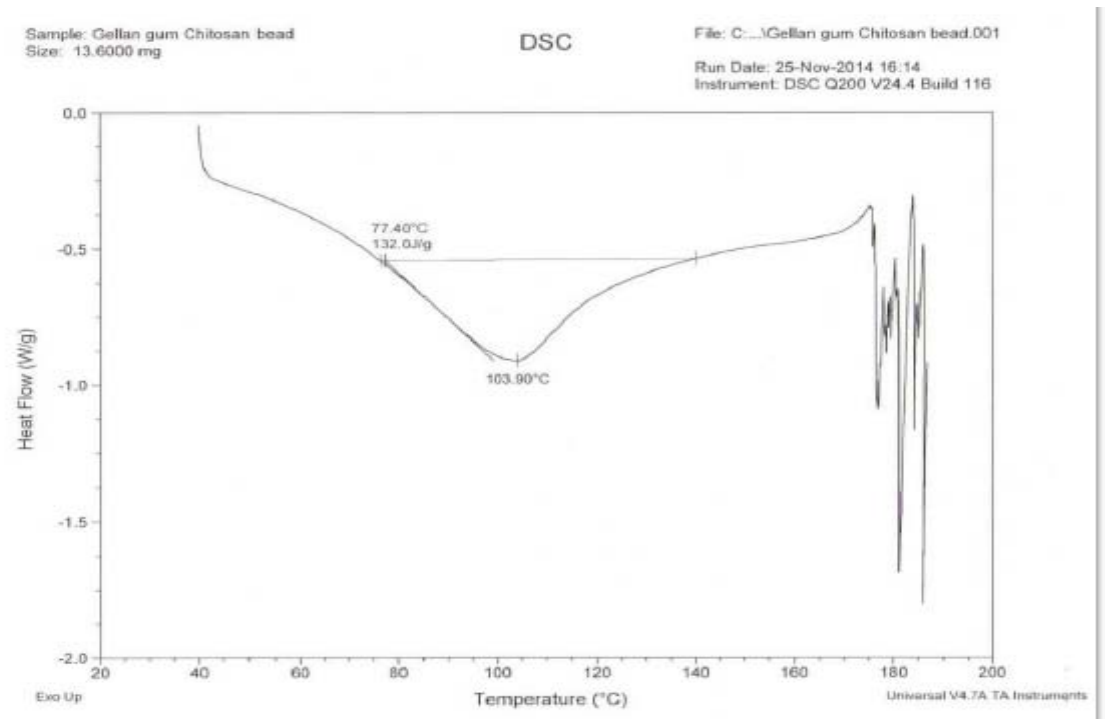

Fig. 7: Differential scanning calorimetry of blank microbeads

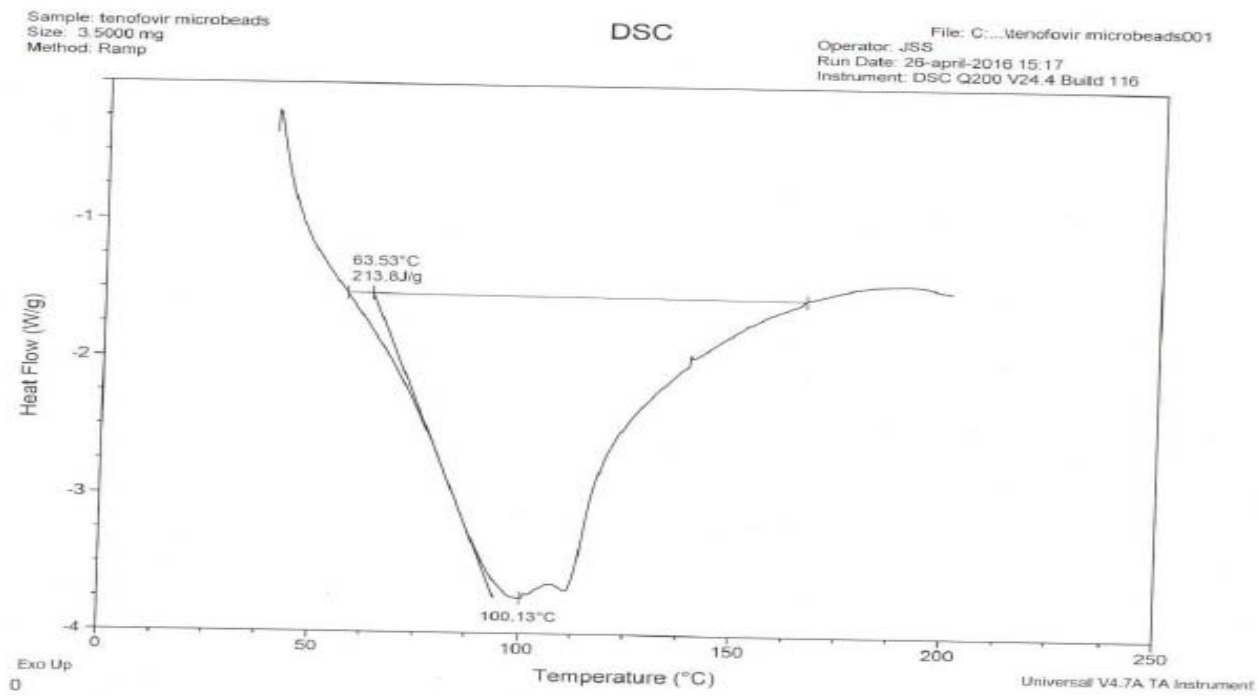

Fig. 8: Differential scanning calorimetry of tenofovir loaded microbeads

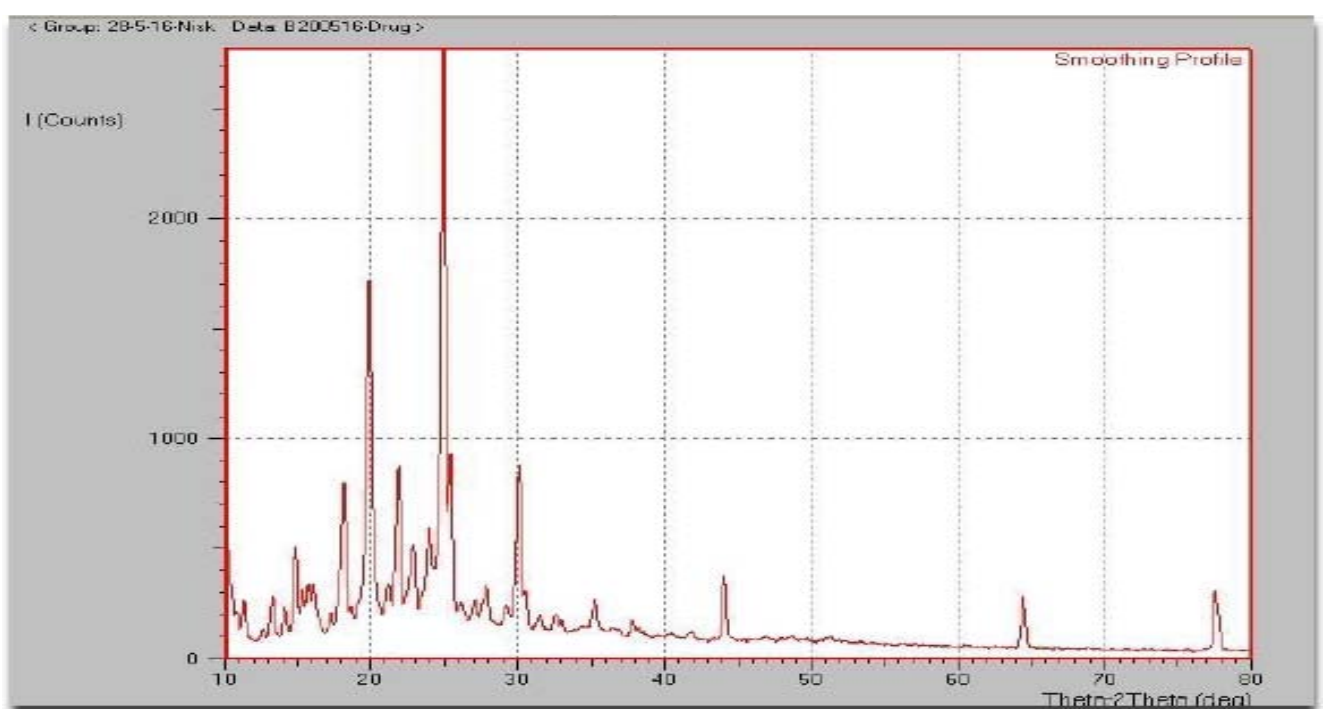

Fig. 9: X-ray diffraction analysis of tenofovir 


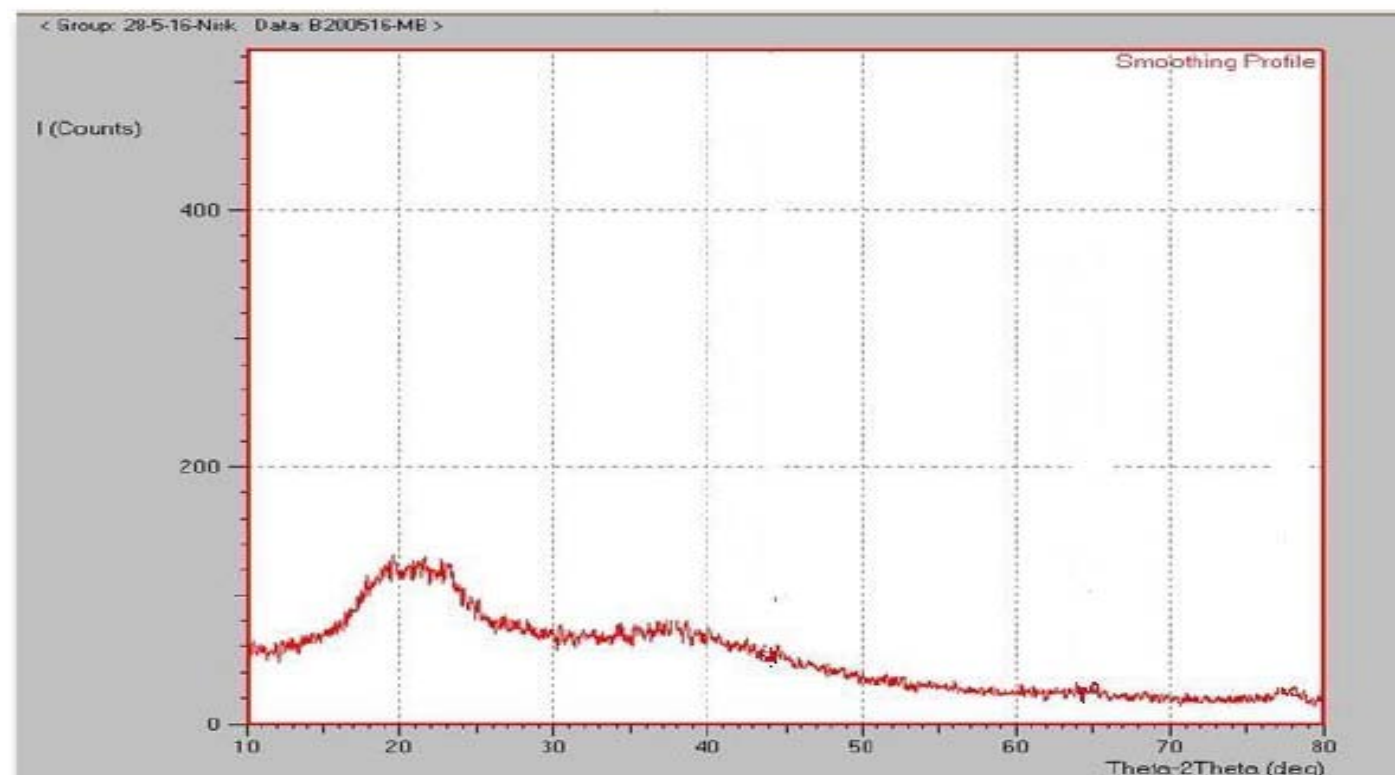

Fig. 10: X-ray diffraction analysis of tenofovir loaded microbeads

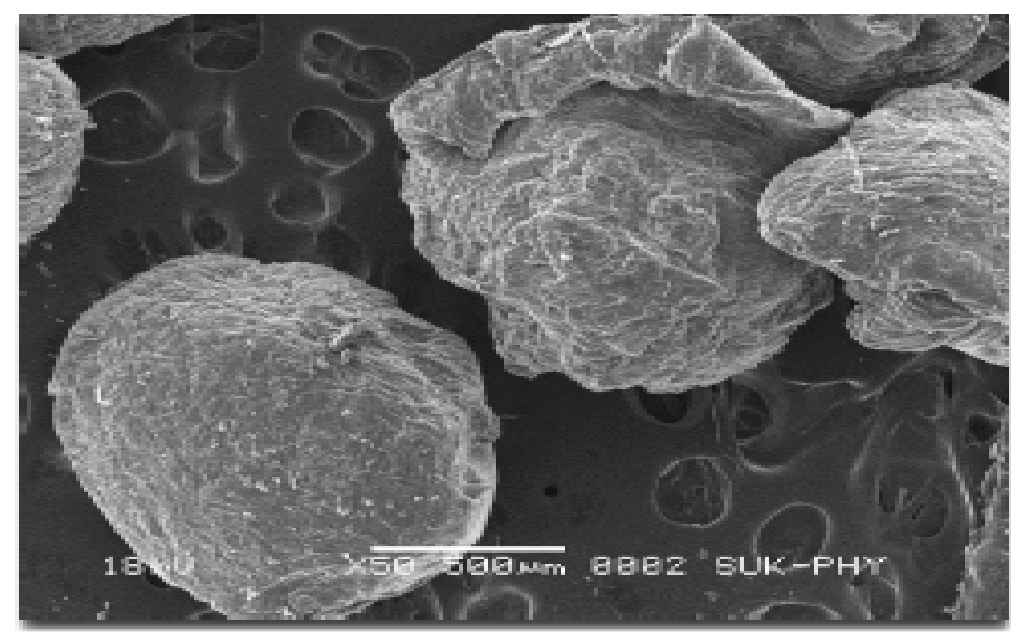

Fig. 11: Scanning electron microscopy (SEM) of tenofovir microbeads

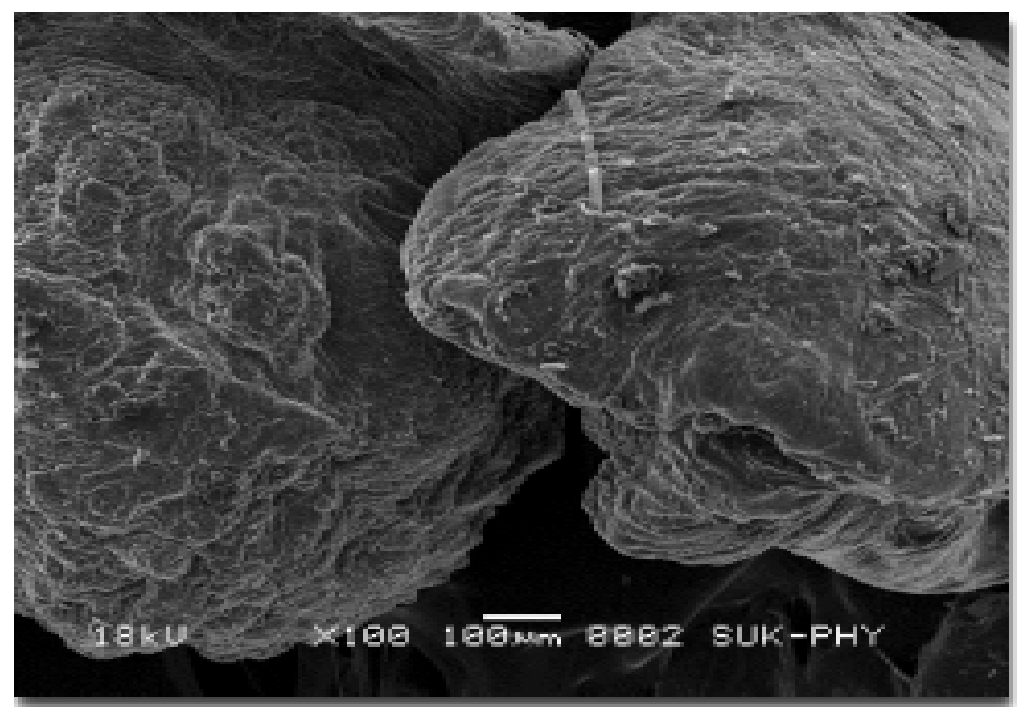

Fig. 12: Scanning electron microscopy (SEM) of tenofovir with dense surface 


\section{In vitro drug release study}

The in vitro release profile of drug loaded beads was depicted in fig 13. From the results it can be observed that the drug release from the beads significantly decreased with an increase in the concentration of the polymer. This could be explained as an increase in the concentration of polymer substantially increases the density of the matrix and diffusional path in which allows the drug molecules to have to traverse. A biphasic pattern of drug release was observed with initial burst effect followed by the sustained release due to the process of gelation as a result of cross linking, which is a characteristic feature of matrix diffusion. It was observed that the initial burst effect of drug was substantially decreased in case of beads coated with chitosan over non-coated beads. The fact could be due to the coating of chitosan exhibited better incorporation efficiency and offered a thick coating over the beads. This could be resulted in the decrease burst effect of the drug from the beads.

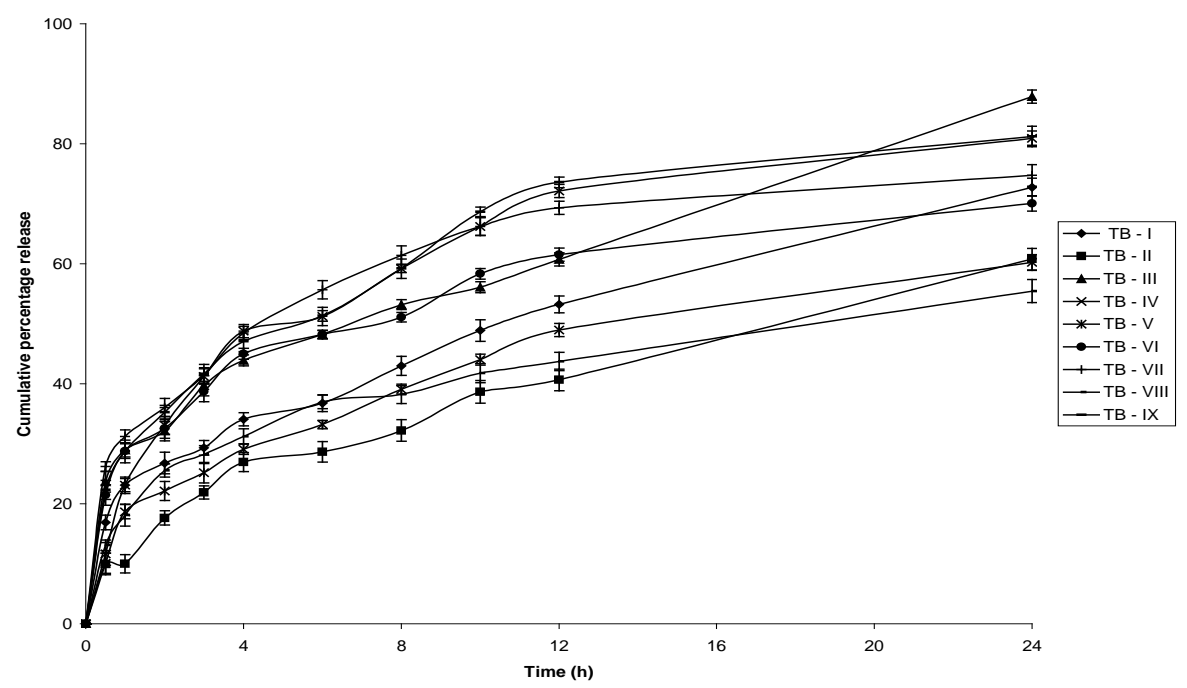

Fig. 13: In vitro release profiles of tenofovir from microbeads (mean $\pm S D, n=3$ )

\section{Release kinetics}

In order to elucidate the mechanism of drug release, the data were fitted into various models such as zero order, first order, Higuchi and Koresmeyar Peppa's. The data's are shown in table 2. The examination of the co efficient of correlation $\left(\mathrm{r}^{2}\right)$ values indicated that the prepared beads followed first order kinetics with non fickian diffusion mechanism of drug release.

Table 2: Regression coefficient ( $\mathrm{r}^{2}$ ) of tenofovir microbeads data from studied matrices according to different kinetic models, diffusion exponent (n) of Peppa's model

\begin{tabular}{|c|c|c|c|c|c|}
\hline \multirow[t]{2}{*}{ Code of formulation } & \multirow{2}{*}{$\begin{array}{l}\text { Zero-order } \\
\left(\mathrm{r}^{2}\right)\end{array}$} & \multirow{2}{*}{$\begin{array}{l}\text { First order } \\
\left(r^{2}\right)\end{array}$} & \multirow{2}{*}{$\begin{array}{l}\text { Higuchi } \\
\left(\mathrm{r}^{2}\right)\end{array}$} & \multicolumn{2}{|c|}{ Peppa's } \\
\hline & & & & n & $\left(r^{2}\right)$ \\
\hline TB-I & 0.711 & 0.972 & 0.921 & 0.622 & 0.913 \\
\hline TB-II & 0.790 & 0.964 & 0.914 & 0.671 & 0.920 \\
\hline TB-III & 0.879 & 0.962 & 0.909 & 0.618 & 0.978 \\
\hline TB-IV & 0.855 & 0.957 & 0.965 & 0.60 & 0.941 \\
\hline TB-V & 0.891 & 0.949 & 0.951 & 0.683 & 0.951 \\
\hline TB-VI & 0.763 & 0.978 & 0.943 & 0.698 & 0.962 \\
\hline TB-VII & 0.845 & 0.981 & 0.978 & 0.614 & 0.974 \\
\hline TB-VIII & 0.862 & 0.944 & 0.936 & 0.711 & 0.928 \\
\hline TB-IX & 0.880 & 0.972 & 0.973 & 0.812 & 0.945 \\
\hline
\end{tabular}

\section{In vitro cytotoxicity assay by MTT method}

The percentage growth inhibition was calculated for the pure drug and drug loaded microbeads needed to inhibit cell growth by $50 \%$ values were generated from the dose-response curves of each cell lines. The IC $\mathrm{C}_{50}$ value for the drug loaded microbeads was found to be $3098.375 \mu \mathrm{g} / \mathrm{ml}$ whereas the pure drug was found to be 202.856 $\mu \mathrm{g} / \mathrm{ml}$.

\section{Bioavailability studies}

The relative bioavailability of the developed microbeads of tenofovir (TB-III) was compared with drug in suspension form. The drug loaded microbeads produced a plasma concentration-time profile typical of the prolonged dissolution characteristic of a sustained release as evident from fig. 14 and table 3. The microbeads formulation demonstrated a longer time to reach a peak concentration than the pure drug in suspension form and appeared to be more consistent in overall performance. This was indicated by lower variation in plasma concentrations, longer time to peak plasma concentration. There was a significant difference in the extent of absorption as assessed by measurements of $\mathrm{AUC}_{\text {o-t }}$. However, $\mathrm{AUC}_{0-\alpha}$ value for the drug loaded microbeads was 1.25 times higher than that of pure drug. The drug loaded microbeads offered more efficient and sustained drug delivery, which would maintain plasma tenofovir levels better. This was also evident by the lower elimination rate $\left(\mathrm{K}_{\mathrm{el}}\right)(1.32$ times lesser for drug in microbeads). The pharmacokinetic parameters of the two different formulations of tenofovir were compared statistically by one way ANOVA (analysis of variance) using SPSS version 13.0. The pharmacokinetic parameters such as $\mathrm{C}_{\max }, \mathrm{T}_{\max }, \mathrm{K}_{\mathrm{el}}, \mathrm{AUC}_{\mathrm{ort}}$ and $\mathrm{AUC}_{\mathrm{o}}$ $\alpha$ of the pure drug and drug loaded microbeads were found to be significantly different $(\mathrm{p}<0.05)$ by one way ANOVA. 


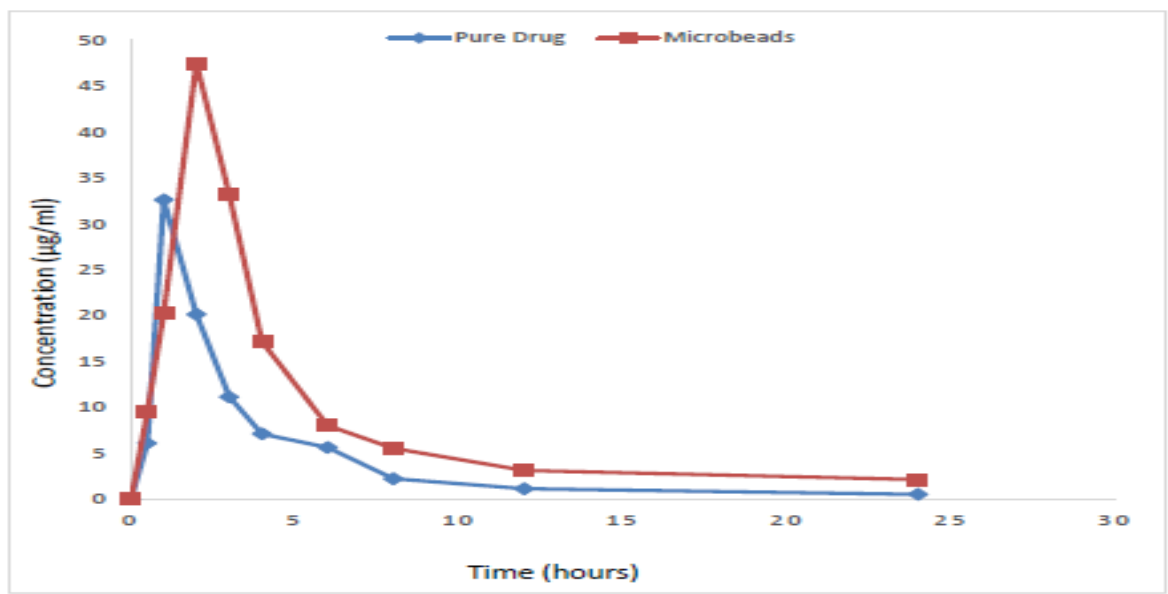

Fig. 14: Mean plasma concentration of pure drug and tenofovir microbeads (mean $\pm S D, n=6$ )

Table 3: Pharmacokinetic profile of pure drug and drug loaded microbeads (mean $\pm S D, n=6$ )

\begin{tabular}{lll}
\hline Pharmacokinetic parameters & Type of formulations \\
\cline { 2 - 3 } & Pure drug & Drug loaded microbeads \\
\hline $\mathrm{C}_{\max }(\mathrm{ng} / \mathrm{ml})$ & $0.3 \pm 0.001$ & $0.38 \pm 0.08$ \\
$\mathrm{~T}_{\max }(\mathrm{h})$ & $1.1 \pm 0.1$ & $1.6 \pm 0.4 \neq$ \\
$\mathrm{AUC}_{\mathrm{o}-\mathrm{t}}(\mathrm{ng} . \mathrm{h} / \mathrm{ml})$ & $2.2 \pm 0.42$ & $2.75 \pm 0.19 \neq$ \\
$\mathrm{K}_{\mathrm{el}}\left(\mathrm{h}^{-1}\right)$ & $0.096 \pm 0.003$ & $0.073 \pm 0.005 \dagger$ \\
$\mathrm{AUC}_{0-\alpha}(\mathrm{ng} . \mathrm{h} / \mathrm{ml})$ & $2.1 \pm 0.05$ & $2.3 \pm 0.06$ \\
\hline
\end{tabular}

$\ddagger$ Significantly higher than pure drug $(\mathrm{p}<0.05)$, †Significantly lower than pure drug $(\mathrm{p}<0.05)$

\section{CONCLUSION}

Tenofovir microbeads were successfully prepared using ionotropic gelation method with moderate entrapment efficiency. A change in the drug crystallinity during the formulation was revealed by DSC and XRD study. FTIR spectral study revealed no chemical change in the microbeads formulation. Tenofovir microbeads exhibited enhanced in vitro cytotoxicity and enhanced oral bioavailability as compared to pure drug. The present investigation demonstrated microbeads as a potential drug delivery system for improving the oral bioavailability of tenofovir.

\section{AUTHORS CONTRIBUTIONS}

First author conceived the idea, second author carried out the research work under the supervision of first and third author. First author drafted the manuscript with the help of third author.

\section{CONFLICTS OF INTERESTS.}

Authors declare no conflicts of interest

\section{REFERENCES}

1. Shefrin S, Sreelaxmi CS, Vishnu V, Sreeja CN. Enzymosomes: a rising effectual tool for targeted drug delivery system. Int J Appl Pharm 2017;9:1-9.

2. Revathy BM, Lakshmi VS, Aishwarya MU, Keerthana R, Sreeja CN. Porphysomes: a paradigm shift in targeted drug delivery. Int J Appl Pharm 2018;10:1-6.

3. Vaizoglu 0, Speiser P. Intelligent drug delivery systems. Trends Pharmacol Sci 1982;3:28-30.
4. Oluwatoyin AO, Adenike 0 , Alf L. Formulation and in vitro evaluation of natural gum-based microbeads for delivery of ibuprofen. Trop J Pharm Res 2014;13:1577-83.

5. Rajinikanth PS, Sankar C, Mishra B. Sodium alginate microspheres of metoprolol tartarate for intranasal systemic delivery. Drug Delivery 2003;10:21-8.

6. Zhang J, XU S, Zhang S, Du Z. Preparation and characterization of tamarind gum/sodium alginate composite gel beads. Iranian Polym J 2008;17:899-906.

7. Odeku OA, Lamprecht A, Okunlola A. Characterization and evaluation of four natural gums as polymers in the formulations of diclofenac sodium microbeads. Int J Biol Macromol 2013;58:113-20.

8. Praksah S, Vidyadhara S, Sasidhar RL, Abhijit D, Akhilesh D. Development and characterization of ritonavir nanosuspension for oral use. Der Pharm Lett 2013;5:48-55.

9. Patil JS, Kamalapur MV, Marapur SC, Shiralshetti SS. Ionotropically gelled novel hydrogel beads: preparation, characterization and in vitro evaluation. Ind J Pharm Sci 2011;73:504-9.

10. Higuchi T. Mechanism of sustained action medication: theoretical analysis of rate of solid drugs dispersed in solid matrices. J Pharm Sci 1963;52:1145-9.

11. Koresmeyer RW, Gurny R, Doelker E, Buri P, Peppas NA. Mechanism of solute release from porous hydrophilic polymers. Int J Pharm 1983;15:25-35.

12. Ritger PL, Peppas NA. A simple equation for description of solute release, I: fickian and non-fickian release from nonswellable devices in the form of slabs, spheres, cylinders (or) discs. J Controlled Release 1985;5:23-35.

13. Sawyer M, Ratain MJ. Body surface area as a determinant of pharmacokinetics and drug dosing. Invest New Drugs 2001;19:171-7. 